\title{
PBBO: A New Approach for Underground Water Analysis
}

\author{
Harish Kundra \\ Head and Asst. Professor \\ Rayat Institute of Engg. and IT
}

\author{
Sumit Kaur \\ M. Tech Student \\ Rayat Institute of Engg., India \\ Dr. R.P.S Bedi \\ Joint Registrar \\ Punjab Technical University \\ Jalandhar
}

\author{
Ashish Verma \\ Asst. Professor \\ SSIET, India
}

\begin{abstract}
From last ten to fifteen years many optimization techniques have been evolved and enhanced. Out of those, PSO and BBO are the two techniques that have been widely used in Swarm Optimization. PSO is better in comparison many genetic algorithms. PSO has applications in various areas like Optimization, Neural Networks training, Fuzzy controls and etc. BBO is based on science of biogeography. BBO has some features common to PSO and Genetic algorithms but it has some important features that make it more reliable than others. In this paper, we have proposed new algorithm that combines the features of PSO and BBO. It will help in providing more reliability in optimization world.
\end{abstract}

\section{KEYWORDS}

PSO, BBO, GA, Optimization, Underground Water Exploration.

\section{INTRODUCTION}

PSO algorithm was in original developed by doctors Eberhart and Kennedy. It was based on stochastic optimization technique. PSO is first populated with random solutions and then search for optimum solution by repetitions. In this method, the behavior of bird is simulated. It is assumed that there are number of birds that are searching food in a location and there is only single piece of pray is present is there. There are only few birds that know where the pray is present. Then the best solution for the remaining birds is that follow the birds which is nearby to pray. In PSO algorithm, bird is known as particle. We use a fitness function in which different values are given to particles which is then optimized. The particles have their particular positions and velocities in starting and then afterwards go on changing in search of pray. After every repetition, every particle updates its two values. First one is the value that it has gained and other one is the best value by optimization that is achieved so far. These are stated as pbest and gbest respectively. The two equations are used by particle to update its velocity and position is

$\operatorname{Vel}[]=\operatorname{Vel}[]+C 1+C 2$

where

$$
C 1=\operatorname{const} 1 * \operatorname{rand}() *(\text { pbest }[]-\text { present }[]
$$

$$
\begin{array}{rl}
C 2=\operatorname{const} 2 & * \operatorname{rand}() \\
& *(\operatorname{gbest}[]-\operatorname{present}[]) \\
\operatorname{present}[] & =\operatorname{present}[]+\operatorname{Vel}[]
\end{array}
$$

and

Here Vel [ ] is the velocity of particle and Present [ ] is current result of particle.const1 and const 2 are learning factors. Here both are takes as 1 .

\subsection{Pseudo Code for PSO is}

For each particle

End

Initialize the particle

Do

For each particle

Find out the fitness value of each particle

If current value of pbest is good against value in history then

Set current value as pbest

End

Select the gbest as the best fitness value of all the particles.

For each particle

Find out the particle velocity for equation 1. End

Increment the position of particle by using equation 2 .

Repeat while maximum iterations or the criteria of minimum error are not attained.

On each position velocity of particle is equated to a maximum velocity as Vmax. If the sum of accelerations try to exceed the velocity from the input value which is given by the researcher then the velocity is limited to Vmax.

BBO (Biogeography Based Optimization) was introduced by simon and is used for global optimization. Here species immigrate or emigrate between islands in search of more friendly habitats. Each result is known as habitat and each has habitat suitability index (HSI) which is a vector. Each individual is represented with some initial random value and good HSI values are retained. Both high and low HSI values share their features. The migration and mutation operators are used for generating the new habitat from the all the solution in the problem. BBO migration is helpful to change present solution and modify existing island. 
The probability $\mathrm{Xi}$ is proportional to the immigration rate $\mathrm{Yi}$ and the source of probability is proportional to the emigration rate $\mathrm{Uj}$.

Procedure for Habitat migration is

Start

$$
\text { For } \mathrm{i}=1 \text { to } \mathrm{N}
$$

Select $\mathrm{Xi}$ with probability based on $\mathrm{Yi}$ if $\operatorname{rand}(0,1)<\mathrm{Yi}$ then

$$
\text { for } \mathrm{j}=1 \text { to } \mathrm{N}
$$

Select Xi with probability based on $\mathrm{Uj}$

if $\operatorname{rand}(0,1)<\mathrm{Uj}$ then

Randomly select an index vector $\sigma$ from Xi

Replace a random vector in $\mathrm{Xi}$ with $\sigma$

end if

end for

end if

end for

End

While mutation is based on probability that modifies the index vectors randomly this depends on the priority of probability of existence. Here we ignore the very high HSI and very low HSI and take the medium HSI.

Procedure for mutation is

Begin

for $\mathrm{i}=1$ to $\mathrm{N}$

calculate the probability $\mathrm{Pi}$

select vector $\mathrm{Xi}(\mathrm{j})$ dependent on $\mathrm{Pi}$

if $\operatorname{rand}(0,1)<\mathrm{mi}$ then

replace $\mathrm{Xi}(\mathrm{j})$ with randomly generated vector

end if

end for

End

The mutation rate is defined as:

$$
m=m_{\max }\left(\frac{1-P_{s}}{P_{\max }}\right)
$$

Here $\mathrm{m}_{\max }$ is user defined and here it is 2 .

Diversity of population is increased by this mutation process.

\section{PROPOSED ALGORITHM}

The proposed enhanced model will use the basics of BBO and PSO.

For each particle

Initialize particle

For each particle

Calculate fitness value

If the fitness value is better than the best fitness value

(pbest) in history

set current value as the new pbest

End

Choose the particle with the best fitness value of all the particles as the gbest
For each particle

Calculate particle velocity according to Eq. 2

Update particle position according to Eq.1

End

Consider each feature as one habitat.

For each particle

Total no. of habitat $=$ universal + feature habitat

Define HSI, Smax, Smin, immigration rate and emigration rate.

Find HSI for each other feature habitat.

Z) Select image area from universal habitat and migrate it to one of the other habitat and recalculate HSI.

If recalculated HSI is within limit then absorb the species to that habitat else.

Check for the other habitats and recalculate the HSI.

If all species in universal habitat are checked then stop else go to step Z.

Continue till max. iterations or min. error criteria is not attained.

Here habitat is group of pixels around corners where pixel with best value is located

\section{ATTRIBUTES USED IN DATASET}

Table 1. List of sample attributes

\begin{tabular}{|l|l|}
\hline Geology & $\begin{array}{l}\text { Sedimentary, Igneous, Metamorphic, } \\
\text { Alluvium }\end{array}$ \\
\hline Soil & Sand, Gravel, Clay or Cracked rock, Silt \\
\hline $\begin{array}{l}\text { Nature of } \\
\text { Land }\end{array}$ & $\begin{array}{l}\text { Agricultural, Coarse sand, Grave land, } \\
\text { Plain, Riverbed, fissured sandstone }\end{array}$ \\
\hline Quality of Soil & $\begin{array}{l}\text { Highly dissolved, low dissolved and } \\
\text { Medium dissolved with organics }\end{array}$ \\
\hline $\begin{array}{l}\text { Thickness of } \\
\text { Soil }\end{array}$ & $\begin{array}{l}\text { Soil }=2 \mathrm{~mm}, \text { Sand }=2-0.05, \\
\text { Silt }=0.05-0.002, \text { Clay }<0.002\end{array}$ \\
\hline $\begin{array}{l}\text { Mineral } \\
\text { present in Soil }\end{array}$ & $\begin{array}{l}\text { Montmorillonite, Illite, } \\
\text { Nontronite, Kaolinite, Hydrated Halloysite, } \\
\text { Chlorite, Attapulgite }\end{array}$ \\
\hline
\end{tabular}

\section{RESULTS}

We first take the sample of soil and then put the attributes in the database and then apply the new algorithm on the dataset. The sample dataset is taken as

Table 2.The sample dataset

\begin{tabular}{|l|l|}
\hline Geology & Alluvium \\
\hline Soil & Clay \\
\hline Nature of Land & Agricultural \\
\hline Quality of Soil & low dissolved with organics \\
\hline Thickness of Soil & Clay $<0.002$ \\
\hline $\begin{array}{l}\text { Mineral present } \\
\text { in Soil }\end{array}$ & Kaolinite \\
\hline
\end{tabular}

Here we emigrate the species to different habitats. The graphs on $\mathrm{X}$ axis shows the values 1, 2 and 3 for Low, medium and high habitat. On $\mathrm{Y}$ - axis the numbers of species are taken. 
Table 3. Shows no. of species before emigration

\begin{tabular}{|c|c|}
\hline Low Habitat & 120 \\
\hline Medium Habitat & 66 \\
\hline High Habitat & 92 \\
\hline
\end{tabular}

Table 4. Shows no. of species after emigration

\begin{tabular}{|c|c|}
\hline Low Habitat & 110 \\
\hline Medium Habitat & 60 \\
\hline High Habitat & 85 \\
\hline
\end{tabular}

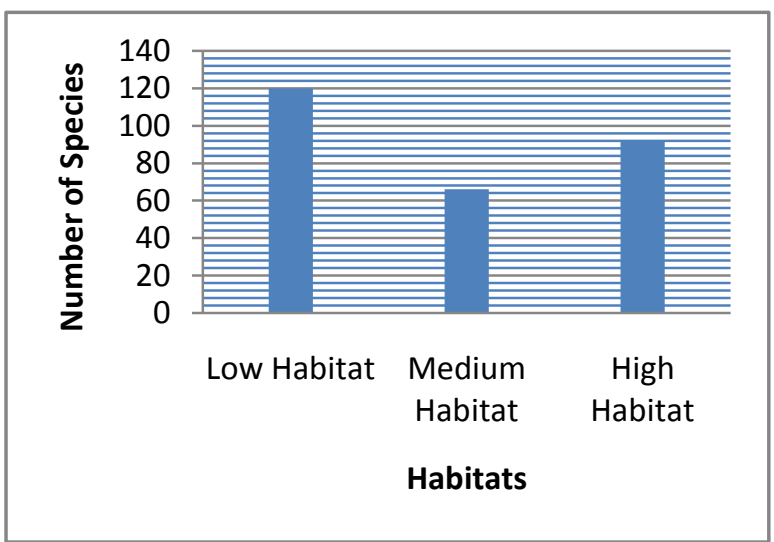

Figure 1: Results before the emigration

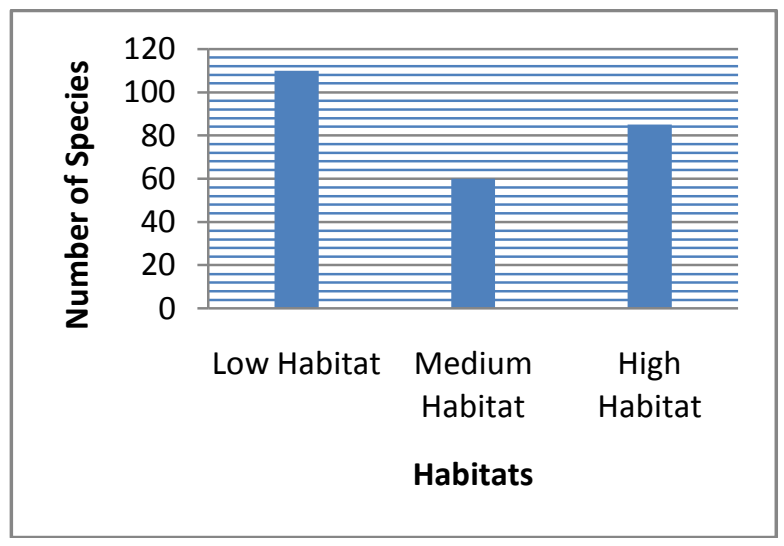

Figure 2: Results after the emigration

\section{COMPARATIVE STUDY}

Now we have made a comparison between the well known algorithm known as PSO (Particle Swarm Optimization). The results are shown below in table number 5 and 6 .

Table 5. Shows no. of species before emigration

\begin{tabular}{|c|c|}
\hline Low Habitat & 120 \\
\hline Medium Habitat & 66 \\
\hline High Habitat & 92 \\
\hline
\end{tabular}

Table 6. Shows no. of species after emigration

\begin{tabular}{|c|c|}
\hline Low Habitat & 101 \\
\hline Medium Habitat & 55 \\
\hline High Habitat & 82 \\
\hline
\end{tabular}

The results show that for PSO there is high rate of emigration in comparison to new proposed approach. In case of low habitat there is approximate 9 percent difference in emigration, in case of medium habitat there is 16 percent drop in emigration and for the high habitat case there is 8 percent drop in emigration.

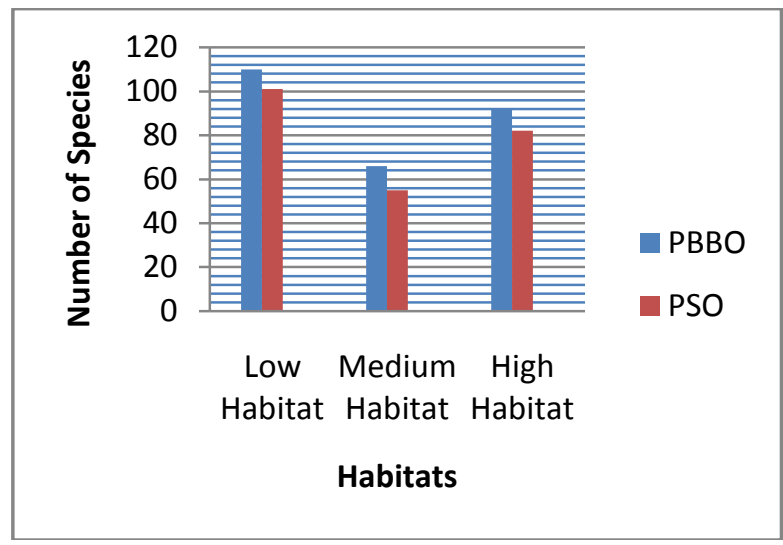

Figure 3: Results after the emigration for the $\mathrm{PBBO}$ and PSO.

\section{CONCLUSION}

In this paper, we used a new approach to measure underground water penetration using PBBO method. PBBO founds the ground water possibility for the given sample is $60 \%$. It is better than many other methods used in the past. PBBO gives much better results than the PSO. In the future we will try to modify the algorithm so that so that better results can be further derived.

\section{REFERENCES}

[1] J. Kennedy, R. C. Eberhart, and Y.Shi, Swarm Intelligence. Morgan Kaufmann Publishers, San Francisco, 2001

[2] 2. H. Sun, Y. Pan, and Y. Zhang, "Pso based gabor wavelet feature extraction method," in Proceedings of the Intern'1 Conference on Information Acquisition, 21-25 June 2004, pp. 422 - 425, 2005.

[3] 3. "Image Enhancement Using Particle Swarm Optimization", Malik Braik, Alaa Sheta and Aladdin Ayesh, Proceedings of the World Congress on Engineering 2007 Vol I. WCE 2007, July 2 - 4, 2007, london, U.K.

[4] 4. "Biogeography Based Groundwater Exploration", V.K.Panchal, Harish Kundra, Amanpreet Kaur, IJCA, 2010.

[5] "A Probabilistic Analysis of a Simplified Biogeography - Based Optimization Algorithm", Dan Simon Cleveland, State University Department of Electrical and Computer Engineering Cleveland, Ohio 44115 February 13, 2009. 
[6] "Comparative Analysis in Medical Imaging", Ashish Verma, Bharti Sharma, IJCA, 2010.

[7] "Study on the behviour of BBO over terrain features", V.K Panchal, Divya Bhugra, Samiksha Goel, Vipul Singhania, IEEE 2011.

[8] F Vanden Bergh, "An Analysis of Particle Swarm Optimizers", PhD Thesis, University of Pretoria, South Africa, 2002.

[9] Kundra Harish and Monica Sood(2010) "Cross-Country Path Finding using Hybrid approach of PSO and BBO"
International Journal of Computer Applications (0975 8887), vol. 7, pp. 6 .

[10] Magnus E. H. pedersen, Hvass Lab (2010), "Good parameters for particle swarm optimization".

[11] Magnus E. H. pedersen, "SwarmOps for matlab: Numeric \& heuristic optimization", Hvass Lab, 2011

[12] 12. Panchal V.K, Goel S. and Bhatnagar M., (2009), "Biogeography Based Land Cover Feature Extraction", IEEE, pp. 1588- 1591. 